\title{
An In Vivo Study to Evaluate the Efficacy of Aloe-Vera and $0.2 \%$ Chlorhexidine Digluconate as Preprocedural Mouth Rinses for Disinfecting Alginate Impression
}

\author{
Tanu Mahajan ${ }^{1}$
}

1Department of Prosthodontics, Rama Dental College and Hospital, Kanpur, Uttar Pradesh, India.

\section{ABSTRACT}

\section{BACKGROUND}

The purpose of this in vivo study was to study the effect of various liquids used as pre-procedural mouth rinses which include water, chlorhexidine gluconate and aloe vera, on alginate.

\section{METHODS}

A total of thirty subjects was selected. For each individual subject, 3 impressions of maxillary arch were made using alginate. Impressions were divided into three categories. First impression (Group 1) was made without using any preprocedural mouth rinse. After the impression was made, a sterile cotton swab was wiped over the impression surface and sent for culture sensitivity test. This swab acted as the control group. The swab was then run over the Blood Agar culture medium. The incubation of culture-medium plates was done for $24 \mathrm{hrs}$. at $37^{\circ} \mathrm{C}$. From the culture plate, smear was taken to examine bacterial growth and the colony forming units were counted on the slide. 24 hours after initial impression, the second impression (Group 2) was made after making the subject rinse with aloe vera for 30 seconds. After 48 hours after Group 1, third impression (Group 3) of the same subject was made, making the subject rinse with $0.2 \%$ chlorhexidine digluconate solution for 30 seconds. Rest of the steps were same for both the impressions as the first impression. Data was recorded and analysis for difference in the bacterial count between Group 1, Group 2 and Group 3 was done using ANOVA with post-hoc Bonferroni test from SPSS version 18.

\section{RESULTS}

The result showed an overall significant difference in the mean CFU among the three groups. Post-hoc test showed that group 1 had significantly higher mean CFU (7.54) than group 2 (2.98) and 3 (1.82). The least bacterial count was seen in the samples in which chlorhexidine digluconate was used as a mouth rinse before making the impression. The mean percentage reduction in bacterial count was 60.33 in the group for which aloe vera was used and 75.81 in the chlorhexidine digluconate group.

\section{CONCLUSIONS}

$0.2 \%$ chlorhexidine digluconate when used as preprocedural mouth rinse for 30 seconds markedly reduces the bacterial growth of aerobic culture. Although Aloe vera does have an antibacterial effect when used as preprocedural mouth rinses when compared with $0.2 \%$ chlorhexidine digluconate, it is a weaker disinfectant. The antibacterial activity of $0.2 \%$ chlorhexidine digluconate is more effective than aloe vera (99.9\%) when used as preprocedural mouth rinse.

\section{KEY WORDS}

Aloe Vera, Antibacterial Activity, Chlorhexidine, Disinfectant, Mouth Rinse
Corresponding Author: Dr. Tanu Mahajan, 117/54, L-Block, Naveen Nagar, Kanpur-208025, Uttar Pradesh, India E-mail: drtanumahajan_27@yahoo.co.in

DOI: $10.14260 /$ jemds/2020/548

How to Cite This Article:

Mahajan T. An in vivo study to evaluate the efficacy of aloe-vera and $0.2 \%$ chlorhexidine digluconate as preprocedural mouth rinses for disinfecting alginate impression. J Evolution Med Dent Sci 2020;9(35):2521-2525, $10.14260 /$ jemds/2020/548

Submission 10-02-2020,

Peer Review 16-07-2020,

Acceptance 23-07-2020,

Published 31-08-2020.

Copyright (C) 2020 JEMDS. This is an open access article distributed under Creative Commons Attribution License [Attribution 4.0 International (CC BY 4.0)] 


\section{BACKGROUND}

A well-made dental impression is the most important step in the fabrication of a well-fitting prosthesis it can be rightly said that it is the backbone of dental procedures. After the impression is made, it is transferred to the dental assistant or the technician for the pouring of the cast. At this stage it becomes very important to take care of the issue of cross infection as the impression comes in contact with the patient's blood, saliva and plaque. All of these contain potential pathogenic microorganisms. Thus, all the people working in the dental office and as well as lab can easily get contaminated. ${ }^{1-3}$ Almost invariably, all the dental impressions do come in contact with blood, plaque and saliva which transmit infection. ${ }^{4}$

The commonly used method of heat sterilization is not possible for dental impressions as it will definitely distort it, so chemical disinfection is the method of choice. The disinfection procedures should be strictly adhered to in the clinic as well as in the lab to prevent the spread of infection. ${ }^{5}$

The prime requisite of any dental impression is its accuracy, thus the disinfectant used should be effective in killing microorganisms without causing any distortion of the impression. Because of this particular problem many clinicians avoid disinfecting alginate, this has prompted the investigators to come up with some other ways; which includes pre-procedural mouth rinsing. ${ }^{6}$ Rinsing with chlorhexidine before the impression procedure has been shown to reduce the aerobic and anaerobic flora of the mouth. ${ }^{7}$

Chlorhexidine antiseptic activity is by the action of membrane disruption of some viruses, and gram positive and gram negative microorganisms.. Chlorhexidine is the most commonly used ingredient in mouthwash which is proven to be effective against dental plaque and oral bacteria. Chlorhexidine gets adsorbed on the enamel surface which is coated with the pellicle layer and there it shows prolong bacteriostatic action, it also shows immediate bactericidal action as the uptake of chlorhexidine by the bacteria is very rapid, acting within 20 seconds. . $^{8-12}$

Aloe vera has been used medicinally for a few thousand years and also finds vivid use in dentistry as well. The antibacterial, antiviral, antifungal action of aloe vera has been documented in several literatures. Aloe vera has been documented to have specific antimicrobial action against (a) Streptococcus pyogenes (b) Staphylococcus aureus (c) Pseudomonas aeruginosa (d) E. coli (e) Mycobacterium tuberculosis (f) Streptococcus viridians (g) Candida albicans (h) Herpes simplex (i) Herpes zoster. ${ }^{13}$

The antimicrobial action of Aloe vera has been found to be due to the anthraquinones which are naturally found in the plant and have demonstrated in-vitro inhibition of Mycobacterium tuberculosis and Bacillus subtilis. Aloe juice also shows bacteriostatic activity against Staphylococcus aureus, Streptococcus pyogenes and also Salmonella paratyphi. ${ }^{14,15}$

\section{METHODS}

This is an in-vivo study conducted in the Department of Prosthodontics, Crown \& Bridge and Implantology, Faculty of Dental Sciences, Rama University, Kanpur. A total of thirty subjects was selected for the study. Three impressions of maxillary arch were made for each subject at 24 hour intervals. The first impression was made without using any mouth rinse, the second after using aloe vera as a mouth rinse and third after using chlorhexidine digluconate as a mouth rinse.

\section{Materials Used}

1. Aloe vera. (99.96\% Pure, Patanjali Ayurved)

2. Chlorhexidine $0.2 \%$.

3. Alginate. (Zelgan 2002)

4. Kidney Tray.

5. Mouth Mirror.

6. Probe.

7. Disposable Glasses.

8. Perforated Dentulous Stock Trays.

9. Rubber Bowl.

10. Curved Spatula.

11. Measuring Scoop and Cylinder.

12. Autoclave

13. Sterile Cotton Swabs.

14. Blood Agar Culture Media.

15. Incubator.

16. Light Microscope.

\section{Exclusion Criteria}

1. Pan chewer.

2. Smoker.

3. Alcoholic.

4. Completely edentulous.

5. Patient undergoing periodontal treatment.

6. Patient undergoing orthodontic treatment.

7. Patient with appliances in oral cavity.

8. Patients with systemic disease.

\section{Inclusion Criteria \\ 1. Healthy Mouth. \\ 2. Patient with all teeth present.}

A total of thirty subjects was selected from student volunteers of Rama Dental College, Kanpur. For each subject, 3 impressions of maxillary arch were made using irreversible hydrocolloid impression material i.e. Alginate (Kromopan Lascod Italy). The subjects were made to sit upright on the dental chair. Conventional sterilization protocols were followed. Autoclaved impression trays were used to make the impressions all the volunteers were given a consent form to be read carefully and then they were asked to sign it. All the instruments needed for mixing alginate such as rubber bowl, curved spatula and perforated metal tray were autoclaved before making the impression. Sterile distilled water in specified quantity as per manufacturer was used for mixing. For each subject 3 maxillary impressions were made. A 24 hour interval was kept between each impression. Three 
categories were made for the impressions thus made, as follows-

\section{Group 1 (Control)}

Alginate impression made without using any mouth rinses before making impression.

\section{Group 2}

Alginate impression made after mouth rinsing with $10 \mathrm{ml}$ of Aloe vera $99.9 \%$ for $30 \mathrm{~s}$.

\section{Group 3}

Alginate impression made after mouth rinsing with $10 \mathrm{ml}$ of Chlorhexidine gluconate $0.2 \%$ for $30 \mathrm{~s}$.

First impression (Group 1) was made by mixing alginate without any mouth rinses. The stainless steel curved mixing spatula and rubber bowl were disinfected with surface chemical disinfectants prior to mixing alginate. Alginate was dispensed in a clean rubber bowl by using scoop provided by the manufacturer and a measuring cylinder was used to dispense the water in a water powder ratio as recommended by the manufacturer. The alginate was mixed using a curved spatula in a figure of eight motion to achieve a smooth creamy consistency and loaded onto the impression tray and the impression was made. After the impression was made, a sterile cotton swab was used and wiped over the impression surface from the centre of the palate and was sent for culture sensitivity test. This swab acted as the control group. The swab was then placed in normal saline transport media and was sent for culture sensitivity test to the Gyan pathology lab, Kanpur. The swab was then run over the Blood Agar culture media. The incubation of culture medium plates was done for 24 hours at $37^{\circ} \mathrm{C}$. From these culture plates, smear was taken on slide to check for the bacterial growth semi quantitatively under light microscope and the colony forming units were then counted. After 24 hours of making the first impressions, the group 2 impressions were made, after making the subjects rinse with aloe vera for 30 seconds. After 48 hours of making the impressions for group 1, the impressions for group 3 were made after making the subject rinse with $0.2 \%$ chlorhexidine digluconate solution for 30 seconds. Rest of the steps were same for both the impressions as the first impression.

\section{Statistical Analysis}

The data thus attained was analysed for difference in the bacterial colony count between Group 1, Group 2 and Group 3 using ANOVA with post-hoc Bonferroni test from SPSS version 18.

\section{RESULTS}

The colony forming units in the 30 samples of group 1 ranged from $1^{*} 10^{7}$ to a maximum of $9^{*} 10.9^{9}$ In group 2 the colony forming units ranged from $1 * 10^{2}$ to $9 * 10.3$ Although it was a significant reduction in the bacterial count, it was far less as compared with group three. The group three showed absolutely no bacterial growth in six samples out of the total thirty samples. Nine samples had less than $1 * 10 .^{2}$ Twelve samples showed the count of less than $5^{*} 10^{2}$ and only three samples had colony forming unit count of more than $5 * 10$. $^{2}$ Thus, it was observed that the third group in which chlorhexidine gluconate was used as a mouth rinse before making alginate impression showed a marked decrease in the bacterial count.

All the analysis was done using SPSS version 18. A p - value of $<0.05$ was considered statistically significant. CFU were log transformed and compared using repeated measures ANOVA with Post-hoc Bonferronitest.

\begin{tabular}{|ccccccccc|}
\hline \multicolumn{1}{|c}{ Group 1 } & \multicolumn{2}{c|}{ Group 2 } & \multicolumn{2}{c|}{ Group 3 } & p-value & Post-hoc \\
& Mean & SD & Mean & SD & Mean & SD & test \\
Log CFU & 7.54 & .29 & 2.98 & .56 & 1.82 & 1.05 & $<0.001 ;$ Sig & $1>2>3$ \\
\hline Table 1. Mean and S.D. of Colony Forming Units of the Three Groups \\
\hline
\end{tabular}

There was an overall significant difference in the mean CFU among the three groups. Post-hoc test showed that group 1 had significantly higher mean CFU than group 2 and 3 . Similarly, Group 2 had significantly higher mean CFU than Group 3. The least CFU is seen in group 3.

\begin{tabular}{|ccc|}
\hline $\begin{array}{c}\text { Mean percentage reduction with After mouth wash with 99.9 \% } \\
\text { Aloe vera }\end{array}$ & 60.33 & 7.65 \\
$\begin{array}{c}\text { Mean percentage reduction after mouth wash with } 0.2 \% \\
\text { Chlorhexidine digluconate }\end{array}$ & 75.81 & 14.07 \\
\hline Table 2. Percentage Reduction in Comparison to Control & \\
\hline
\end{tabular}

Table 2 shows percentage reduction in comparison to control. Group 3 shows significant decrease of $75.81 \pm 14.07$ $\%$ from Group 1. Group 2 shows a significant decrease of 60.33 $\pm 7.65 \%$ from Group 1 .

\section{DISCUSSION}

Results of this study being very conclusive, clearly show that there is a marked reduction in the growth of the aerobic bacteria following preprocedural mouth rinses with aloe vera and chlorhexidine digluconate. The results show that there is a 60.33 percent reduction in the aerobic bacterial count following mouth rinses with Aloe vera solution (99.9\%) for 30 seconds and 75.81 percent reduction in the aerobic bacterial count following mouth rinses with chlorhexidine digluconate $(0.2 \%)$ for 30 seconds. The results also significantly proved that $0.2 \%$ chlorhexidine digluconate much more effective in reduction of bacterial count than $99.9 \%$ aloe vera as a pre procedural mouth rinses. Saliva and blood of the patient contain microorganisms which contaminate the impressions. ${ }^{16-19}$ Alginate is the most popular and widely used impression material all over the world. But an often overseen drawback of alginate impressions is in its ease of getting contaminated with the microorganisms which are present in the oral cavity. This is due to its composition, surface texture and hydrophilic setting mechanisms. ${ }^{20}$ As alginate sets by a sol-gel mechanism, the microorganisms present in the oral fluids can become incorporated into the gelling impression material. ${ }^{21,22}$ Just because of its surface texture and porosity 
and the setting mechanism it has been seen that the concentration of bacteria is $3-4$ times greater in alginate as compared to rubber base impression materials. ${ }^{17,23}$ The loose matrix structure of the alginate provides an ideal microenvironment for the retention and growth of bacteria. ${ }^{21}$ Because of these porosities the organisms can penetrate deeper levels which are not accessible for the disinfectants. This entrapment of the microorganisms into the matrix makes rinsing with water ineffective, and also this gel structure inhibits penetration of the disinfectant. ${ }^{21}$ For any disinfectant, there are two requirements, first is that it should have an effective antimicrobial action, yet it should cause no distortion of the impression and maintain the surface details of the recorded impression. ${ }^{24}$ Research over the years has proved that alginate impressions are one of the most important carriers in the chain of infection. ${ }^{25,26}$ In terms of irreversible hydrocolloids, disinfection can be performed by numerous methods, and all have their advantages and limitations. ${ }^{27}$ Alginates are hydrophilic in nature and any change in osmotic potential following immersion in any liquid leads to water imbibition, causing it to swell. But when the osmotic potential is reversed, the alginate shows syneresis, causing water to diffuse out which causes shrinkage of the material. These processes of syneresis and imbibition can take place simultaneously, leading to distortion, which causes alginates to be very unpredictable following immersion disinfection. Thus the accuracy of impressions is greatly hampered leading to flawed clinical results. ${ }^{28}$ Due to this property of alginate different researchers have tried various ways to disinfect alginate. The earlier researchers suggested rinsing the impression under running tap water but this was later found out to be an ineffective method of infection control. ${ }^{16}$ It was found that with this method only up to $40 \%$ of the contaminating bacteria could be removed from the impression. ${ }^{21}$ Immersing the impression in chemical disinfectants (e.g. $1 \%$ sodium hypochlorite solution) has another major drawback of jeopardizing the surface details of the impression which could affect the final result of dentures ${ }^{29}$ and show significant distortion. ${ }^{30}$ The results of this study clearly depicts that $0.2 \%$ chlorhexidine digluconate when used as preprocedural mouth rinses for 30 seconds markedly reduces the bacterial growth of aerobic culture. Although Aloe Vera does have an antibacterial effect when used as pre procedural mouth rinses when compared with $0.2 \%$ chlorhexidine digluconate, it is a weaker disinfectant.

There is a marked reduction in the growth of the aerobic bacteria following preprocedural mouth rinses with aloe vera and chlorhexidine digluconate. The results show that there is a 60.33 percent reduction in the aerobic bacterial count following mouth rinses with Aloe vera solution (99.9\%) for 30 seconds and 75.81 percent reduction in the aerobic bacterial count following mouth rinses with chlorhexidine digluconate $(0.2 \%)$ for 30 seconds. The results also significantly proved that $0.2 \%$ chlorhexidine digluconate much more effective in reduction of bacterial count than $99.9 \%$ aloe vera as a pre procedural mouth rinses.

\section{CONCLUSIONS}

Aloe vera has antibacterial activity when used as preprocedural mouth rinse. Chlorhexidine digluconate $(0.2 \%)$ has antibacterial activity when used as preprocedural mouth rinse. The antibacterial activity of $0.2 \%$ chlorhexidine digluconate is higher than that of aloe vera (99.9\%) when used as preprocedural mouth rinse.

However, further investigations and studies are required to evaluate the efficacy of Aloe vera as a disinfectant on anaerobic bacteria, viruses and fungi. There is a vast scope of further studies that can be done in future on this miraculous natural plant product to provide a better understanding of its various effects and possible applications in prosthodontics like effect of aloe vera as a disinfectant on other impression materials, as an internal disinfectant, as disinfecting agent for dentures etc.

Financial or Other Competing Interests: None.

\section{REFERENCES}

[1] Gladwin M, Bagby M. Disinfection of impressions, dentures and other appliances and materials. In: Stewart MA, Gladwin MA, Bagby MD. Clinical aspects of dental materials. $1^{\text {st }}$ edn. Philadelphia: Lippincott Williams and Wilkins 2000:262-7.

[2] Kotsiomiti E, Tzialla A, Hatjivasiliou K. Accuracy and stability of impression materials subjected to chemical disinfection - a literature review. J Oral Rehabil 2008;35(4):291-9.

[3] Yuzbasioglu E, Sarac D, Canbaz S, et al. A survey of crossinfection control procedures: knowledge and attitudes of Turkish dentists. J Appl Oral Sci 2009;17(6):565-9.

[4] Samaranayake LP, Hunjan M, Jennings KJ. Carriage of oral flora on irreversible hydrocolloid and elastomeric impression materials. J Prosthet Dent 1991;65(2):244-9.

[5] Al-Omari WM, Jones JC, Wood DJ. The effect of disinfecting alginate and addition cured silicone rubber impression materials on the physical properties of impressions and resultant casts. Eur J Prosthodont Restor Dent 1998;6(3):103-10.

[6] Guidelines for infection control in the dental office and the commercial dental laboratory. Council on dental therapeutics. Council on prosthetic services and dental laboratory relations. J Am Dent Assoc 1985;110(6):96972.

[7] Veksler AE, Kayrouz GA, Newman MG. Reduction of salivary bacteria by pre-procedural rinses with chlorhexidine 0.12 \%. J Periodontol 1991;62(11):649-51.

[8] Powell GL, Runnels RD, Saxon BA, et al. The presence and identification of organisms transmitted to dental laboratories. J Prosthet Dent 1990;64(2):235-7.

[9] Gerhardt DE, Sydiskis RJ. Impression materials and virus. J Am Dent Assoc 1991;122(5):51-4.

[10] Rice CD, Dykstra MA, Gier RE, et al. Microbial contamination in four brands of irreversible hydrocolloid impression materials. J Prosthet Dent 1991;65(3):419-23. 
[11] Kern M, Rathmer RM, Strub JR. Three-dimensional investigation of the accuracy of impression materials after disinfection. J Prosthet Dent 1993;70(5):449-56.

[12] Langenwalter EM, Aquilino SA, Turner KA. The dimensional stability of elastomeric impression materials following disinfection. J Prosthet Dent 1990;63(3):270-6.

[13] Atherton P. How does aloe vera work? In: Atherton P, ed. The essential aloe vera. $2^{\text {nd }}$ edn. Newport: Mills Enterprises 1997: p. 35.

[14] Olaleye MT, Bello-Michael CO. Comparative antimicrobial activities of aloe vera gel and leaf. Afr J Biotechnol 2005;4(12):1413-4.

[15] Reynolds T, Dweck AC. Aloe vera leaf gel: a review update. J Ethno Pharmacol 1999;68(1-3):3-37.

[16] Clare C. Cross-contamination control in prosthodontics practice. Int J Prosthodont 1991;4(4):337-44.

[17] Samaranayake LP, Hunjan M, Jennings KJ. Carriage of oral flora on irreversible hydrocolloid and elastomeric impression materials. J Prosthet Dent 1991;65(2):244-9.

[18] Egusa H, Watamoto T, Abe $K$, et al. An analysis of the persistent presence of opportunistic pathogens on patient-derived dental impressions and gypsum casts. Int J Prosthodont 2008;21(1):62-8.

[19] Egusa H, Watamoto T, Abe K, et al. Clinical evaluation of the efficacy of removing microorganisms to disinfect patient-derived dental impressions. Int J Prosthodont 2008;21(6):531-8.

[20] Junevicius J, Pavilonis A, Surna A. Transmission of microorganisms from dentists to dental laboratory technicians through contaminated dental impressions. Stomatol Balt Dent Maxillofac J 2004;6(1):20-3.

[21] Beyerle MP, Hensley DM, Bradley DV, et al. Immersion disinfection of irreversible hydrocolloid impressions with sodium hypochlorite: part I: microbiology. Int J Prosthodont 1994;7(3):234-8.
[22] Surna R, Junevicius J, Rutkauskas E. In vitro investigation of the integration depth of oral fluids and disinfectants into alginate impressions. Stomatologija 2009;11(4):12934.

[23] Casemiro LA, Souza FD, Panzeri $\mathrm{H}$, et al. In vitro antimicrobial activity of irreversible hydrocolloid impressions against 12 oral microorganisms. Braz Oral Res 2007;21(4):323-9.

[24] Taylor RL, Wright PS, Maryan C. Disinfection procedures: their effect on the dimensional accuracy and surface quality of irreversible hydrocolloid impression materials and gypsum casts. Dent Mater 2002;18(2):103-10.

[25] Watkinson AC. Disinfection of impressions in UK dental schools. Br Dent J 1988;164(1):22-3.

[26] Ramer MS, Gerhardt DE, McNally K. Accuracy of irreversible hydrocolloid impression materials mixed with disinfectant solutions. J Prosthodont 1993;2(3):1568.

[27] Powell GL, Runnels RD, Saxon BA, et al. The presence and identification of organisms transmitted to dental laboratories. J Prosthet Dent 1990;64(2):235-7.

[28] Muzaffar D, Braden M, Parker S, et al. The effect of disinfecting solutions on the dimensional stability of dental alginate impression materials. Dent Mater 2012;28(7):749-55.

[29] Panza LHV, Porto VC, Salvandor MCG, et al. Evaluation of dimensional stability of impression materials immersed in disinfectant solutions using a metal tray. Revista Odonto Ciencia 2006;21(53):261-5.

[30] Martin N, Martin MV, Jedynakiewicz NM. The dimensional stability of dental impression materials following immersion in disinfecting solutions. Dent Mater 2007;23(6):760-8. 